Editorial

\title{
European Cities Planning for Asylum
}

\author{
Frank Eckardt \\ Institute for European Urban Studies, Bauhaus-Universität Weimar, 99425 Weimar, Germany; \\ E-Mail: frank.eckardt@uni-weimar.de
}

Submitted: 19 November 2018 | Published: 20 December 2018

\begin{abstract}
Despite the high priority refugees are given in the public and political discussion, urban planning has not yet started to systematically consider the role of planning in asylum policy. Mostly, the subject of refugees' arrival is addressed in local projects and housing without framing challenges and opportunities in the national and European context. A wider discussion on the used terminology of "integration" is missing just as much as a self-critical reflection on the orientation of planning discourses on the issue of housing only. In this editorial, our thematic issue "European Cities Planning for Asylum" is introduced and presented.
\end{abstract}

\section{Keywords}

accommodation; asylum; cities; Europe; housing; refugees; segregation; urban planning

\section{Issue}

This editorial is part of the issue "European Cities Planning for Asylum", edited by Frank Eckardt (Bauhaus-Universität Weimar, Germany).

(C) 2018 by the author; licensee Cogitatio (Lisbon, Portugal). This article is licensed under a Creative Commons Attribution 4.0 International License (CC BY).

\section{Introduction}

European asylum policies have been a hot topic for many years now. As a major political subject in many European countries, the question on how to deal with the arrival of refugees in Europe remains highly controversial and has had a major impact on the rise of populism. Surveys show that it is not the that the European citizens reject refugees in general but are not accepting the way the process of integration is organized (Connor, 2018). The European states are failing, in the opinion of many of their citizens, to ensure the integration of refugees, which in return led to the creation of a "crisis". The talk about the "refugee crisis" has proliferated and originated a broader narrative of scepticism about the European unification, and even more about liberal democracy. It appears true that there is a need to consider the instruments, policies, strategies and narratives in asylum planning for refugees in Europe.

It seems obvious therefore, that the discipline of urban planning would be strongly contributing its builtup wisdom and knowledge in reaction to the publicly problematized-and partly truly problematic-situation of refugees in European cities. In fact, scholarly response to the arrival of refugees has stayed local or national but it has not yet reached a European level of reflection. While a sense of urgency has become alarming in many parts of Europe, Urban Planning has not yet found a common ground in searching for solutions.

The differences in planning systems and approaches across Europe are certainly an obstacle to the creation of any kind of European planning policy for asylum. It is, however, too early to draw any conclusion on the potential frames for such a policy and the probability-or even the desirableness - of a unified European approach. So far, even an overview of the different national asylum systems and their relationship to urban planning is missing.

\section{Content}

It is the intention of this thematic issue to contribute to the creation of a systematic knowledge of how different national planning systems and cultures are related to the integration of refugees in local contexts. A wide range of questions are related to the subject of asylum in the city, which the following articles have taken up. The different 
case studies need to be regarded as reflections on the different roles of the planning institutions and national legal frameworks. It is assumed commonly that urban planning does not only fulfil a role within a complex field of relationships to other institutions; it also works with its own concepts, narratives, and interpretations of what is perceived as necessary for the integration of refugees. Especially housing strategies for refugees and their impact on the individual integration in society in general are at the core of these articles.

In this first place, the idea of settlement and camps as the only subject in urban planning regarding refugees needs to be overcome. As Dalal, Darweesh, Misselwitz and Steigemann (2018) convincingly argue in their article, refugees are urban actors practicing spatial behaviour, which has a transformative impact even in the classical refugee camp. Taking the topic of asylum seriously, however, more conceptual reconsiderations about planning are becoming obvious.

If urban planning is no longer thought of as a topdown management affair, the inclusion of citizens becomes especially important in regard to asylum. As d'Auria, Daher and Rohde (2018) work out in their article based on a comparative study of three European cities, urban planning might not have the right narrative for such an integrative approach. They suggest shifting from terms like integration to narratives of solidarity.

In Doomernik and Ardon (2018), the discrepancies between the local and national level regarding the hosting of refugees have been identified as a reason for the inadequacy of contemporary planning approaches in Europe. The investigation of the role of cities in the Europeanization of asylum policies (the so-called Common European Asylum System/CEAS) demonstrates the leaking integration of cities in the discussion of integration of refugees, especially into the labour market.

The differences between local approaches is also the starting point for Neis, Meier and Furukawazono (2018), who look at three examples from Germany. Here, the focus lies on how German citizens and refugees interact and integrate, especially with regard to the spatial dimension of integration. Urban architecture projects for housing and work opportunities are seemingly most important in the first "cycle" of integration, which advocates for an approach that does not reduce urban planning to hosting refugees somehow and somewhere but works with a long term perspective and holistic. Werner et al. (2018) are as well pointing at the importance of local policies. However, their work underlines the contestation of these policies towards refugees in the specific context of urban development. As exemplified in the case of Leipzig, the local approach towards refugees needs to be contextualized in the conflictual situation of housing in general and national governance strategies.

Meier (2018), in an article on the Dutch case of Kerkrade, frames the question of refugee integration also into an analysis of state-city relationships. She frames her analysis in the broader discussion on scale in Urban
Studies. The term does not only reflect morphological or administrative conceptualisation but is motivated by a residential and economical categorisation. The focus on scale can help understanding the interplay of refugees with their socio-spatial fields of opportunities, especially in mid-sized cities. Researching two cities of the same category in Germany, Seethaler-Wari (2018) takes a different approach and argues for the importance of institutional settings in cities and neighbourhoods. In her article, she also looks at the urban context in its complexity but puts emphasis, also, on the attitude of refugees.

The attitudes of refugees might not be something that can be seen as static, and more research needs to be undertaken in order to understand the intersections between the relationships of refugees and hosting communities. Czischke and Huisman (2018), with their ethnographic work in Amsterdam, have indicated that social mix and the self-organisation of refugees are promising subjects for future urban planning and integration policies.

\section{Perspectives}

The articles in this thematic issue are provoking further research in different directions. By looking at asylum policies in Europe, discussions in urban planning of a more profound nature are addressed. Urban planning in this context needs to be understood as institution of a multi-layered state. Competences and obligations, relationships to other institutions and to the citizenry are framed by the wider political system and, to some extent, by the European unification process. In this regard, the concept of "urban governance" (Le Galès, 2003) as a broadening of the state activities to steer society seems to be at stake. While governance theories look at the embedding of planning, planning as a cultural setting (Othengrafen, 2012) based on specific narratives, institutional dynamics, internal conceptualisation and self-interpretation is important with regard to the attitude of urban planners towards refugees. Despite similar European approaches towards refugees, different understandings of planning concepts and discourses on the local and national level are interfering with a future concept for European asylum planning policies. A European planning for integration will remain a weak legal concept and, therefore, requires a massive work of interpretation by planners themselves.

\section{Conclusion}

Cities, as all articles in this issue demonstrate, are the political and spatial field for the integration of refugees. Research on this field works with the assumption that cities are the main field of integration of refugees. Nonetheless, so far, research has not made a strong case in seeing refugees as a special group and rather see refugees as being the same as any kind of migrant (Borkert, Bosswick, Heckmann, \& Lüken-Klaßen, 2007). Current research has identified different dynamics of integration 
which unfold after the settlement of migrants (Poteet \& Nourpanah, 2016). This, so far, has been confirming the relevance of housing location for the further development of the induvial integration process. The physical access to jobs, education, social infrastructure and urban amenities remains of crucial significance, as well as the question of neighbourhood effects, segregation and spatial mismatch.

While this thematic issue has not paid much attention to the definition of the "refugee" it is clear that urban planning cannot escape defining the social group that is here addressed. In practice, a special policy for a group that skips even a clear juridical category might contradict universal approaches in urban planning, like housing for all. Nevertheless, refugees are a particular group of inhabitants which are characterized by specific social aspects, in particular the remaining uncertainty regarding their asylum status, their future position in society, the possibilities of return to their home country. The question remains open in how far the social abilities of refugees to integrate society are based on their psychological well-being (Black, 2001) and how this is supported by urban planning practices and policies.

Supported by observations in most EU countries, planning and management of hosting refugees has been resulting so far in a housing situation that is characterized by social and physical segregation. However, new approaches to segregation support the assumption that not only housing segregation needs to be considered but all domains which are relevant in everyday life likewise (van Ham \& Tammaru, 2016). This leads to the conceptualisation of local integration and urban planning that needs to go beyond the providence of housing for refugees and to a holistic plan for social integration in general and a reconsideration of the terminology of integration in general.

\section{Conflict of Interests}

The author declares no conflict of interests.

\section{References}

Black, R. (2001). Fifty years of refugee studies: From theory to policy. International Migration Review, 35(1), 57-78.

Borkert, M., Bosswick, W., Heckmann, F., \& LükenKlaßen, D. (2007). Local integration policies for migrants in Europe. Bamberg: European Forum for Migration Studies.
Connor, P. (2018). A majority of Europeans favor taking in refugees, but most disapprove of EU's handling of the issue. Pew Research Center. Retrieved from www. pewresearch.org/fact-tank/2018/09/19/a-majorityof-europeans-favor-taking-in-refugees-but-most-dis approve-of-eus-handling-of-the-issue

Czischke, D., \& Huisman, C. J. (2018). Integration through collaborative housing? Dutch starters and refugees forming self-managing communities in Amsterdam. Urban Planning, 3(4), 156-165.

d'Auria, V., Daher, R., \& Rohde, K. (2018). From integration to solidarity: Insights from civil society organisations in three European cities. Urban Planning, 3(4), 79-90.

Dalal, A., Darweesh, A., Misselwitz, P., \& Steigemann, A. (2018). Planning the ideal refugee camp? A critical interrogation of recent planning innovations in Jordan and Germany. Urban Planning, 3(4), 64-78.

Doomernik, J., \& Ardon, D. (2018). The city as an agent of refugee integration. Urban Planning, 3(4), 91-100.

Le Galès, P. (2003). Le retour des villes européennes: Sociétés urbaines, mondialisation, gouvernement et gouvernance [The return of European cities: Urban societies, globalization, government and governance]. Paris: Les Presses de Sciences Po.

Meier, S. (2018). Being accommodated, well then? 'Scalar narratives' on urban transformation and asylum seekers' integration in mid-sized cities. Urban Planning, 3(4), 129-140.

Neis, H. J., Meier, B., \& Furukawazono, T. (2018). Welcome city: Refugees in three German cities. Urban Planning, 3(4), 101-115.

Othengrafen, F. (2012). Uncovering the unconscious dimensions of planning: Using culture as a tool to analyse spatial planning practices. London: Routledge.

Poteet, M., \& Nourpanah, S. (Eds.). (2016). After the flight: The dynamics of refugee settlement and integration. Cambridge: Cambridge Scholars Publishing.

Seethaler-Wari, S. (2018). Urban planning for the integration of refugees: The importance of local factors. Urban Planning, 3(4), 141-155.

van Ham, M., \& Tammaru, T. (2016). New perspectives on ethnic segregation over time and space. A domains approach. Urban Geography, 37(7), 953-962.

Werner, F., Haase, A., Renner, N., Rink, D., Rottwinkel, M., \& Schmidt, A. (2018). The local governance of arrival in Leipzig: Housing of asylum-seeking persons as a contested field. Urban Planning, 3(4), 116-128.

\section{About the Author}

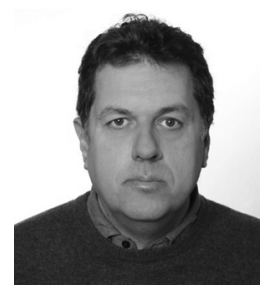

Frank Eckardt is a Professor for Urban Studies and Social Research at the Institute for European Urban Studies, Bauhaus-Universität Weimar. His main fields of research are social inequalities and cultural diversities in cities. Most recently, his book on anti-asylum protests in East-Germany (Ungeliebte Nachbarn: Anti-Asyl-Proteste in Thüringen) has been published by transcript publishers, Bielefeld (2018). 